\title{
SISTEM KEAMANAN BERBASIS ALARM IP CAMERA DENGAN PASSIVE INFRARED RECEIVER (PIR) SENSOR DAN SMS GATEWAY
}

\section{IP-BASED SECURITY ALARM SYSTEM WITH CAMERA PASSIVE INFRARED RECEIVER (PIR) SENSOR AND SMS GATEWAY}

\author{
Hafiidh As Syahidulhaq. ${ }^{1}$, Hafiddudin $^{2}$, Suci Aulia ${ }^{3}$ \\ ${ }^{1,2,3}$ Prodi D3 Teknik Telekomunikasi, Fakultas Ilmu Terapan \\ Universitas Telkom \\ 1hafiidh.as.syahidulhaq@gmail.com²hafid@tass.telkomuniversity.ac.id \\ suciaulia@telkomuniversity.ac.id
}

\begin{abstract}
Abstrak
Penelitian mengenai security sytem sekarang ini sedang ramai diperbincangkan. Beberapa diantaranya adalah dengan menggunakan CCTV, dengan adanya rekaman CCTV ini sangat memudahkan bagi para penyelidik untuk mengetahui tindak kejahatan yang terjadi, namun penggunaan CCTV untuk merekam secara terus menerus selama waktu tertentu umtuk mendapat visualisasi kejadian yang lengkap membutuhkan kapasitas memori yang besar sehingga tidak efisien. Pada penelitian ini diimplementasikan sistem keamanan alarm CCTV network atau biasa disebut dengan Kamera IP dengan menggunakan PIR (Passive Infrared Receiver) sebagai sensor untuk mendeteksi gerak manusia sehingga CCTV hanya akan merekam pada saat terjadi pergerakan manusia dengan mendeteksi perubahan suhu disekitarnya, pada saat terdeteksi adanya pergerakan manusia yang tertangkap di kamera IP akan membunyikan alarm dan mengirimkan notifikasi pesan singkat ke ponsel genggam pemilik CCTV menggunakan SMS Gateway dan terekam oleh CCTV sehingga dapat dilihat melalui aplikasi pada smartphone atau PC. secara realtime. Penelitian dilakukan dengan cara memasang kamara IP dan SMS gateway di kamar kost dan PC serta smart pendeteksi dilakukan di kampus. Dari hasil pengukuran, sensor PIR dapat mendeteksi suhu dengan jarak terjauh 4 meter. Lamanya buzzer menyala adalah 50.67 detik. Apabila buzzer aktif, maka sms akan terkirim secara otomatis pada smartphone, adapun delay ratarata pengiriman notifikasi sms adalah 5.2 detik. Parameter QoS yang terukur yaitu, packet loss sebesar 0,2\%, delay 0,0038 second/packet, dan throughput sebesar 2,028 Mbit/sec.
\end{abstract}

\section{Kata kunci : CCTV, IP Camera, PIR sensor, alarm, SMS Gateway}

\section{Abstract}

Research on security sytem is currently busy discussed. Some of them are using CCTV, with CCTV footage is very easy for investigators to determine the crimes committed, but the use of CCTV to record continuously for a certain time the team to get a visualization of events complete requires a large memory capacity so inefficient. In this study, implemented security alarm system CCTV network or commonly called the IP camera by using PIR (Passive Infrared Receiver) as a sensor for detecting human motion so that CCTV will only be recorded in the event of human movement by detecting changes in temperature surrounding it, when the detected movement man who was caught in the IP camera will sound an alarm and sends a notification short messages to mobile phones using SMS Gateway and recorded by CCTV so that it can be viewed through an 
application on a smartphone or PC. in realtime. The study was conducted by installing IP cameras and SMS gateway in a boarding room and PCs as well as smart detection is done on campus. From the measurement results, PIR sensor can detect temperature with the furthest distance of 4 meters. The duration of 50.67 seconds is lit buzzer. When the buzzer is active, then the SMS will be sent automatically to the smartphone, while the average delay sending sms notification is 5.2 seconds. Measurable QoS parameters, namely, $0.2 \%$ packet loss, delay 0.0038 second / packet, and a throughput of $2.028 \mathrm{Mbit} / \mathrm{sec}$.

\section{Keywords: CCTV, IP Camera, PIR sensor, alarm, SMS Gateway, security}

\section{PENDAHULUAN}

Pada penelitian sebelumnya [1], telah diimplementasikan suatu system keamanan berbasis video dan sensor PIR. Pada penelitian tersebut dijelaskan bahwa sistem bekerja setelah sensor PIR berhasil mendeteksi suhu manusia, kemudian hasilnya berupa dikirim berupa teks ke smartphone sebagai informasi. Penelitian lainnya [2], setelah sensor PIR berhasil mendeteksi suhu manusia dilanjutkan dengan menampilakan video pada LCD. Adapun penelitian lainnya [3], keluaran dari sensor PIR dijadikan masukkan untuk PC dengan menggunakan matlab untuk mendeteksi keberadaan manusia. Apabila manusia terdeteksi, maka buzzer akan berbunyi. Berdasarkan beberapa penelitian tersebut, maka nilai tambah pada penelitian ini adalah sistem keamanan alarm CCTV network atau biasa disebut dengan Kamera IP dengan menggunakan PIR (Passive Infrared Receiver). PIR sensor sebagai pendeteksi gerak manusia disisi alarm dan dapat mengirimkan notifikasi pesan singkat ke ponsel genggam pemilik CCTV menggunakan SMS Gateway bila terdeteksi ada pergerakan manusia yang tertangkap di kamera IP.

\section{DASAR TEORI}

\section{PIR(Passive Infrared Receiver)}

PIR merupakan salah satu sensor yang menggunakan infrared untuk mendeteksi suatu benda. PIR berbeda dengan IR LED (Infra Red Light Emiting Diode), IR LED dapat memancarkan cahaya namun tidak dengan sensor PIR. PIR bekerja dengan cara merespon energi dari pancaran infrared pasif yang terpasang pada setiap benda, contohnya adalah tubuh manusia. Energi pasif tersebut merupakan energi panas dengan batas minimum suhu adalah nol derajat. Adapun bagian dari PIR adalah lensa Fresnel, Filter infra merah, sensor pyroelectrik, penguat amplifier, dan Komparator.Blok diagramdari PIR dapat dilihat pada Gambar 1.

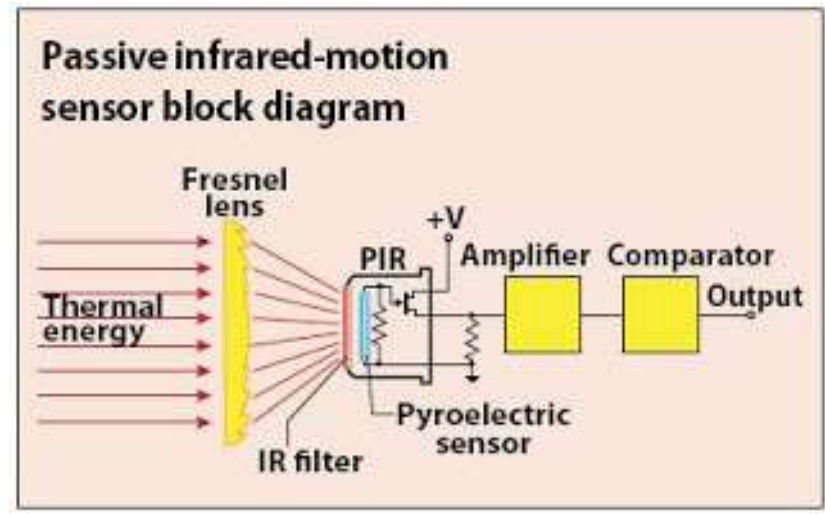

Gambar 1. Blok diagram sensor PIR 


\section{METODOLOGI PENELITIAN} dibawah ini:

Secara umum pemodelan sistem aplikasi pembaca warna ditunjukan pada Gambar 2

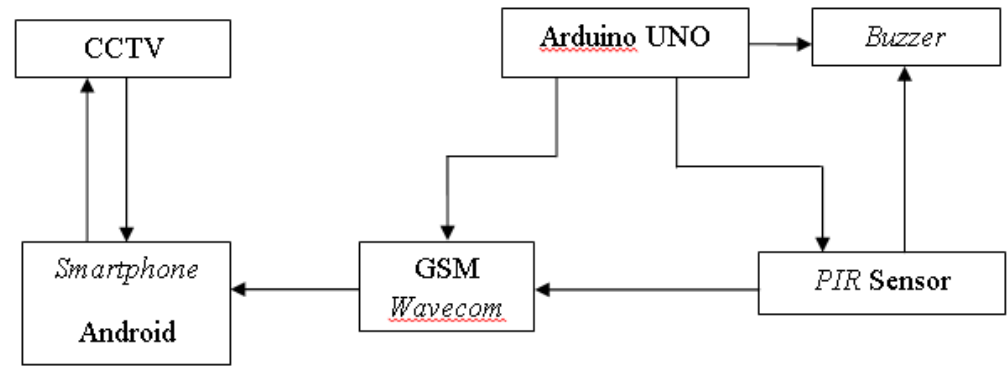

Gambar 2. Blok sistem perancangan aplikasi

Dari Gambar2, dapat dijelaskan bahwa sistem keamanan bekerja saat sensor PIR mendeteksi adanya gerakan manusia. Pertama-tama sistem keamanan harus dalam keadaan standby, dengan begitu ketika sensor PIR aktif maka akan memberikan perintah kepada Arduino untuk mengaktifkan peringatan dengan membuat Buzzer berbunyi.

Setelah itu pemilik alarm akan mendapatkan notifikasi berisi pesan singkat untuk membuka software CCTV IP yang telah terinstall dari nomor modem Wavecom yang telah dipasang. Berikut ini adalah cara kerja sistem keamanan yang digunakan saat sensor PIR mendeteksi pergerakan manusia :

- $\quad$ Alarm Buzzer akan berbunyi ketika sensor PIR mendeteksi adanya gerakan manusia selama 30 detik hingga tidak terdeteksi lagi gerakan manusia.

- $\quad$ Modem Wavecom GSM akan mengirimkan SMS ke pemilik CCTV untuk segera membuka software CCTV tersebut serta mengecek dan melihat secara langsung kejadian yang sedang terjadi pada saat itu..

- $\quad$ SMS akan dikirim Modem Wavecom GSM ke pemilik tiap satu menit sekali saat sensor PIR masih mendeteksi pergerakan manusia.

\section{Prinsip Kerja Sistem}

Berikut ini adalah prinsip kerja dari sistem .

- Koneksi Arduino dengan Sensor PIR dan Buzzer.

Sensor PIR adalah sebagai input dan buzzer sebagai output dari alat ini, sensor PIR menggunakan port A0 sebagai masukkan serta port gnd dan vcc sebagai tegangan. Sensor ini akan bekerja jika mendeteksi pergerakan manusia. Modul PIR hanya membutuhkan tegangan input DC 5 volt, cukup efektif untuk mendeteksi gerakan hingga jarak deteksi 4 meter. Ketika tidak mendeteksi gerakan, output modul adalah LOW. Dan ketika mendeteksi adanya gerakan, maka output akan berubah menjadi HIGH.

Buzzer menggunakan port A1 sebagai masukkan data dan port gnd sebagai tegangan. Buzzer akan berbunyi selama 50 detik saat sensor PIR mendeteksi pergerakan manusia. Lamanya buzzer berbunyi adalah yang sesuai dengan standar ketentuan sistem keamanan yaitu $50-60$ detik. Ilustrasinya dapat dilihat pada Gambar 3 (a) dan Gambar 3(b).

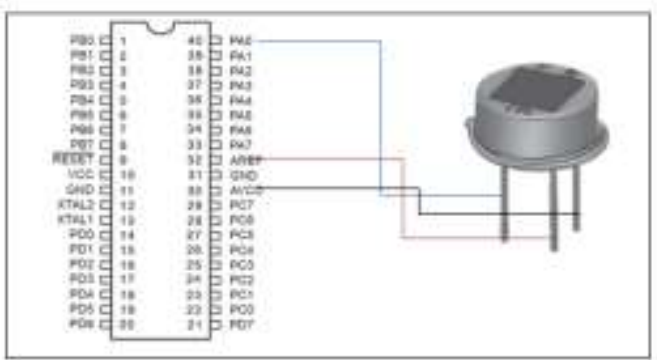

(a)

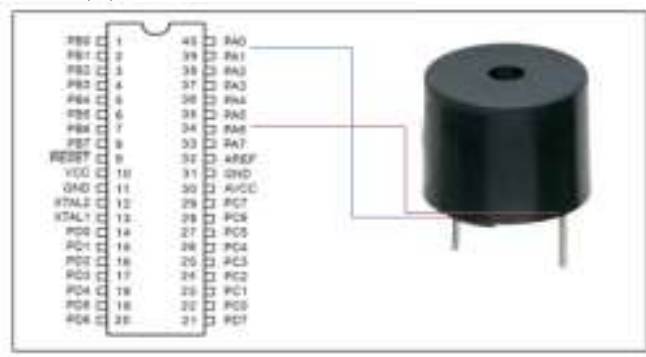

(b)

Gambar 3. (a) Koneksi Arduimo dengan sensor PIR (b) Koneksi Arduimo dengan Buzzer. 
- $\quad$ Koneksi Arduino dengan Modem Wavecom

Koneksi antara arduino dengan Modem Wavecom menggunakan komunikasi serial to RS232 Converter. Pada arduino, pin 2 menjadi pin RX, sedangkan pin 3 digunakan sebagai TX. Lalu pada serial to RS232 converter, pin 11 pada max232 dihubungkan ke pin 3 yaitu TX pada arduino, sedangkan pin 12 pada max232 dihubungkan ke pin 2 arduino. Untuk membuat serial to RS232 converter aktif, maka pin 16 pada max232 dihubungkan ke pin $5 \mathrm{~V}$ pada arduino, sedangkan pin 15 pada max232 dihubungkan ke pin GND pada arduino.Ilustrasinya dapat dilihat pada Gambar 4.

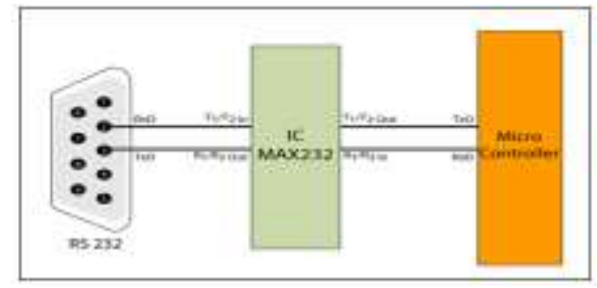

Gambar 4. Interkoneksi Arduimo Dengan Converter Wavecom.

- $\quad$ Koneksi Modem Wavecom dan Smartphone (SMS Gateway).

SMS gateway pada alat ini menggunakan modem wavecom pada sisi pengirim, dan pada sisi penerima terdapat smartphone lengkap dengan simcard-nya sebagai sarana untuk membuka software IP camera. Gambar 5 merupakan ilustrasi dari perancangan sistem SMS gateway yang digunakan.

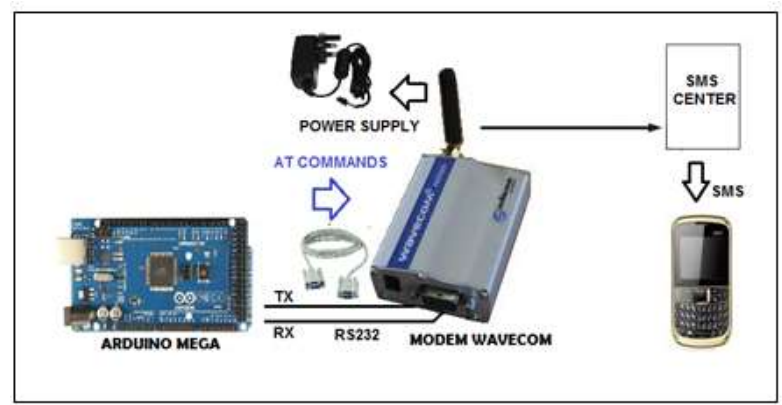

Gambar 5. Perancangan modem wavecom.

\section{HASIL DAN ANALISIS}

\subsection{Pengujian Sensor Gerak PIR}

Pada bagian ini akan dijelaskan mekanisme sensor PIR. Yang pertama sensor ini dihubungkan ke Arduino di port A0, kemudian hubungkan Arduino dengan adaptor. Setelah terhubung maka sensor PIR akan mendeteksi pergerakan manusia dalam suatu ruangan. Sensor telah diuji dengan cara mengarahkan sensor tersebut ke bagian tubuh, kemudian LED salah satu Arduino akan menyala. Jika sensor PIR aktif, maka alarm buzzer akan aktif. Hasil pengujian ditampilkan pada Tabel 1 .

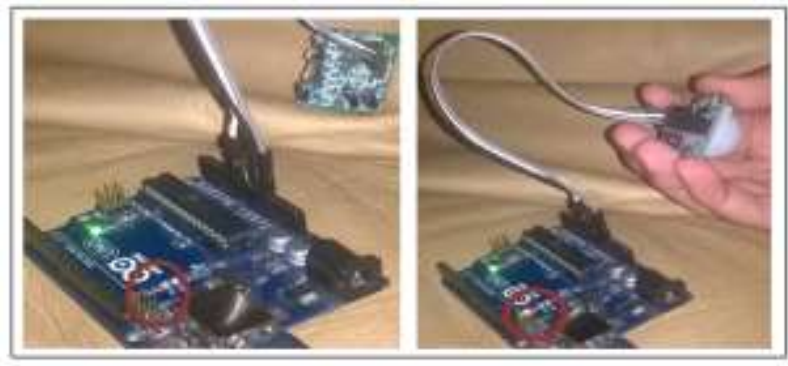

Gambar 6. Pengujian Sensor PIR 
Dari Gambar.6, dapat dilihat bahwa input sensor PIR diaktifkan melalui script di Arduino IDE dan dapat dilihat status aktifnya sensor melalui serial monitor. Nantinya jika terdeteksi manusia, maka tampilan serial monitor akan ada status terdeteksi. Dan jika nantinya gerakan manusia tidak dapat dibaca sensor PIR pada jarak tertentu, maka tampilan serial monitor tidak ada input terdeteksi.

Tabel 1. Hasil Pengujian PIR Sensor

\begin{tabular}{cccc}
\hline Pengujian ke- & Percobaan & Jarak Deteksi (Meter) & Status \\
\hline $\mathbf{1}$ & $3 \mathrm{Kali}$ & $0,5 \mathrm{Meter}$ & Terdeteksi Manusia \\
$\mathbf{2}$ & $3 \mathrm{Kali}$ & $1 \mathrm{Meter}$ & Terdeteksi Manusia \\
$\mathbf{3}$ & $3 \mathrm{Kali}$ & $2 \mathrm{Meter}$ & Terdeteksi Manusia \\
$\mathbf{4}$ & $3 \mathrm{Kali}$ & $3 \mathrm{Meter}$ & Terdeteksi Manusia \\
$\mathbf{5}$ & $3 \mathrm{Kali}$ & $4 \mathrm{Meter}$ & Terdeteksi Manusia \\
$\mathbf{6}$ & $3 \mathrm{Kali}$ & $5 \mathrm{Meter}$ & Tidak Terdeteksi \\
$\mathbf{7}$ & $3 \mathrm{Kali}$ & $6 \mathrm{Meter}$ & Tidak Terdeteksi \\
$\mathbf{8}$ & $3 \mathrm{Kali}$ & $7 \mathrm{Meter}$ & Tidak Terdeteksi \\
$\mathbf{9}$ & $3 \mathrm{Kali}$ & $8 \mathrm{Meter}$ & Tidak Terdeteksi \\
$\mathbf{1 0}$ & $3 \mathrm{Kali}$ & 9 Meter & Tidak Terdeteksi \\
\hline
\end{tabular}

Tabel 1 merupakan hasil pengujian deteksi jarak manusia terhadap sensor PIR. Berdasarkan hasil pengujian, dapat disimpulkan bahwa jangkauan optimal sensor PIR terhadap gerakan manusia adalah 0 hingga jarak maksimal 4 meter. Di atas jarak tersebut, sensor tidak dapat mendeteksi gerakan manusia.

\subsection{Pengujian Buzzer}

Setelah buzzer terhubung dengan arduino (port 7), hubungkan script buzzer dan sensor PIR didalam Arduino agar dapat dikombinasikan. Kemudian, hubungkan Arduino dengan adaptor. Setelah terhubung, maka buzzer akan berbunyi saat sensor PIR mendeteksi gerakan manusia. Buzzer akan aktif selama 50 detik tiap sensor PIR bekerja. Hasil pengujian dapat dilihat pada Gambar 7 dan Tabel 2.

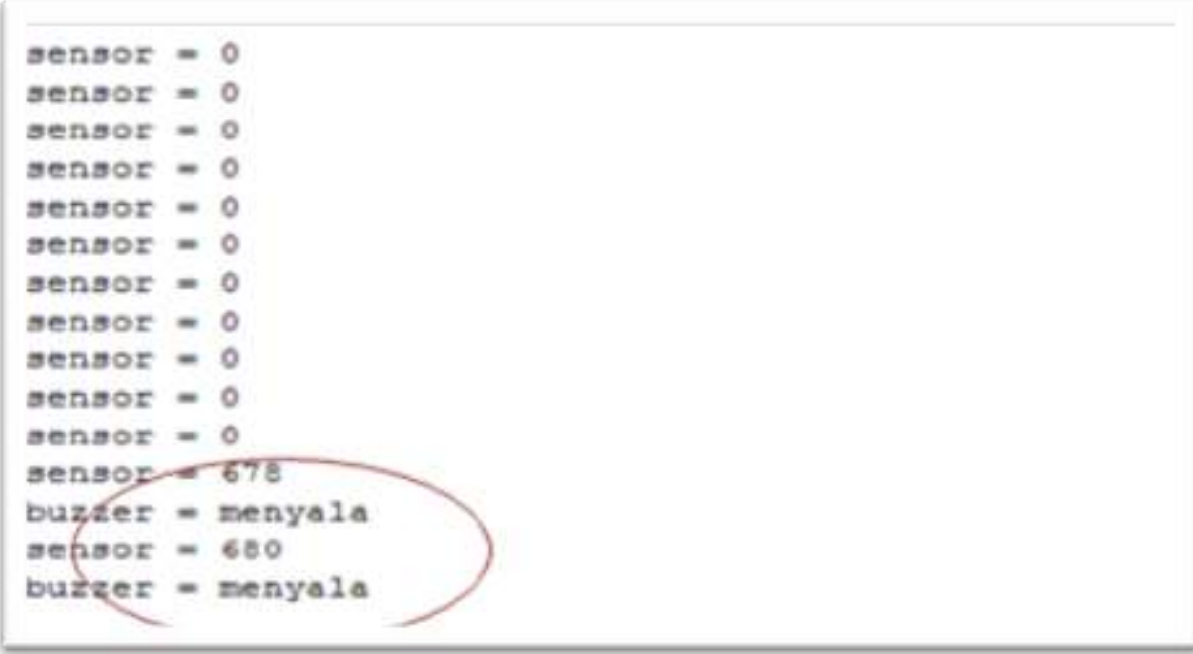

Gambar 7. Hasil Pengujian Buzzer dalam Serial Monitor Arduino 
Tabel 2. Hasil Pengujian Buzzer

\begin{tabular}{cc}
\hline Pengujian Sensor PIR & Lamanya Buzzer Menyala \\
\hline Pengujian Ke- 1 & 50, 08 Detik \\
\hline Pengujian Ke- 2 & 50, 85 Detik \\
Pengujian Ke- 3 & 51,09 Detik \\
Rata - rata & 50,67 Detik \\
\hline
\end{tabular}

\subsection{Pengujian Notifikasi SMS}

Proses yang dilakukan pada pengujian adalah mengaktifkan sensor PIR. Setelah sensor aktif, maka SMS notifikasi akan dikirim melalui Arduino berupa informasi ada tidaknya pergerakan manusia. Selain itu, dilakukan juga pengukuran untuk waktu pengiriman hasil notifikasi sms dari modem wavecom ke smartphone. Gambar 8(a) dan Gambar 8(b) memperlihatkan mekanisme dari rangkaian RS232 converter dan Notifikasi SMS yang terkirim.

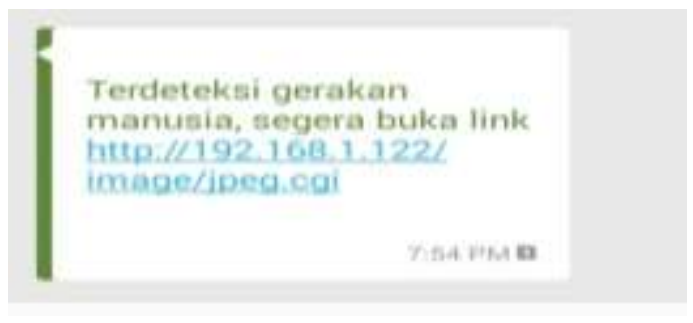

(a)

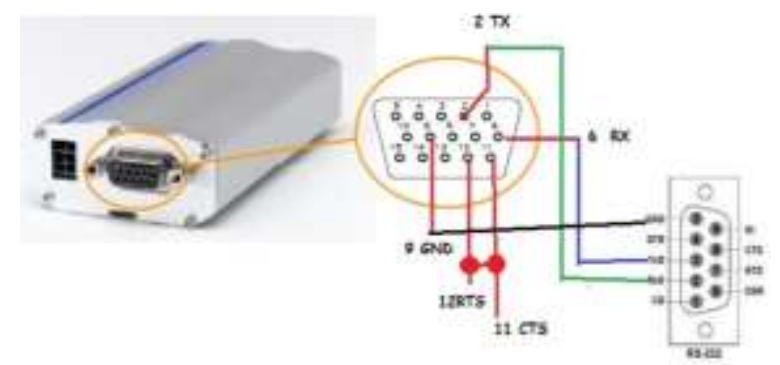

(b)

Gambar 8. (a) Hubungan serial Wavecom dan RS232 (b) Isi SMS pada samartphone

Tabel 3 berikut merupakan hasil pengukuran untuk respon delay dari SMS yang terkirim. Dari hasil pengujian dapat disimpulkan bahwa delay sms yang terkirim bermacam-macam, hal ini dikarenakan kondisi jaringan seluler pada saat pesan dikirim .

Tabel 3. Hasil Pengujian SMS

\begin{tabular}{cc}
\hline Pengujian Notofikasi & $\begin{array}{c}\text { DELAY } \\
\text { SMS (s) }\end{array}$ \\
\hline Pengujian Ke- 1 & 5 \\
\hline Pengujian Ke- 2 & 4 \\
\hline Pengujian Ke- 3 & 3 \\
\hline Pengujian Ke- 4 & 9 \\
Pengujian Ke- 5 & 6 \\
Rata-rata & 5,4 \\
\hline
\end{tabular}

\subsection{Hasil konfigurasi dan pengujian IP Camera}

Berikut adalah tatacara konfigurasi Protocol di modem ADSL speedy. Langkah pertama yaitu membuka browser lalu ketik default IP modem ADSL (192.168.1.1) speedy pada URL, kemudian masukkan :"username: admin, dan password: admin". Pilih "Advanced Setup" pada pilihan set up seperti pada Gambar 9, lalu dipilih "NAT" dan masuk ke "Virtual Server". Input nama "Application" bebas, ganti protocol dengan TCP, start port dan end port diisi dengan 80. Ubah "local IP Address" dengan "192.168.1.112" yaitu IP default yang terdapat pada IP Camera. Tampilan Status IP Camera pada Local Host dapat dilihat pada Gambar 10. 


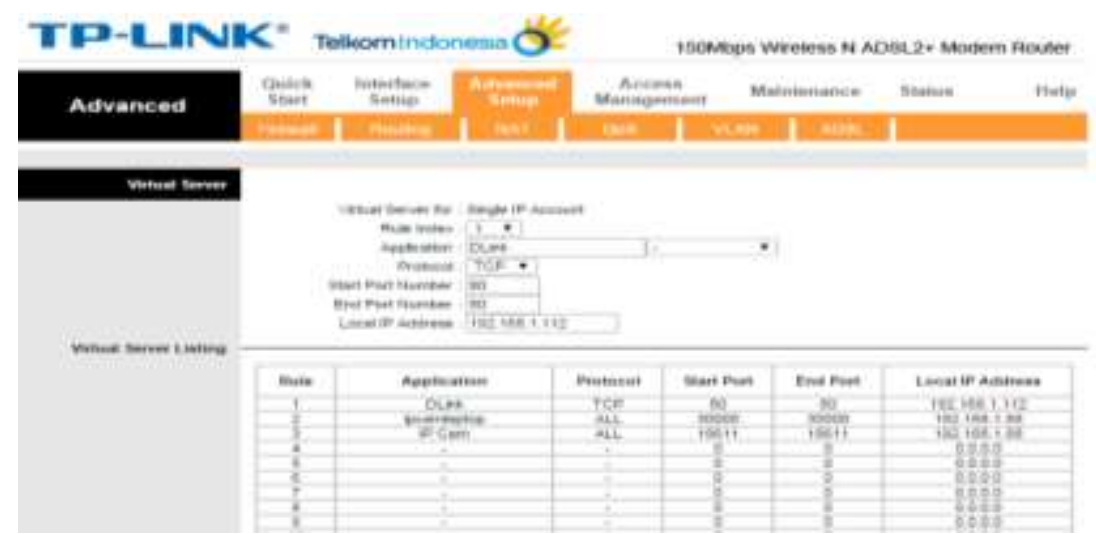

Gambar 9 . Hasil Konfigurasi TCP pada modem dan router ADSL

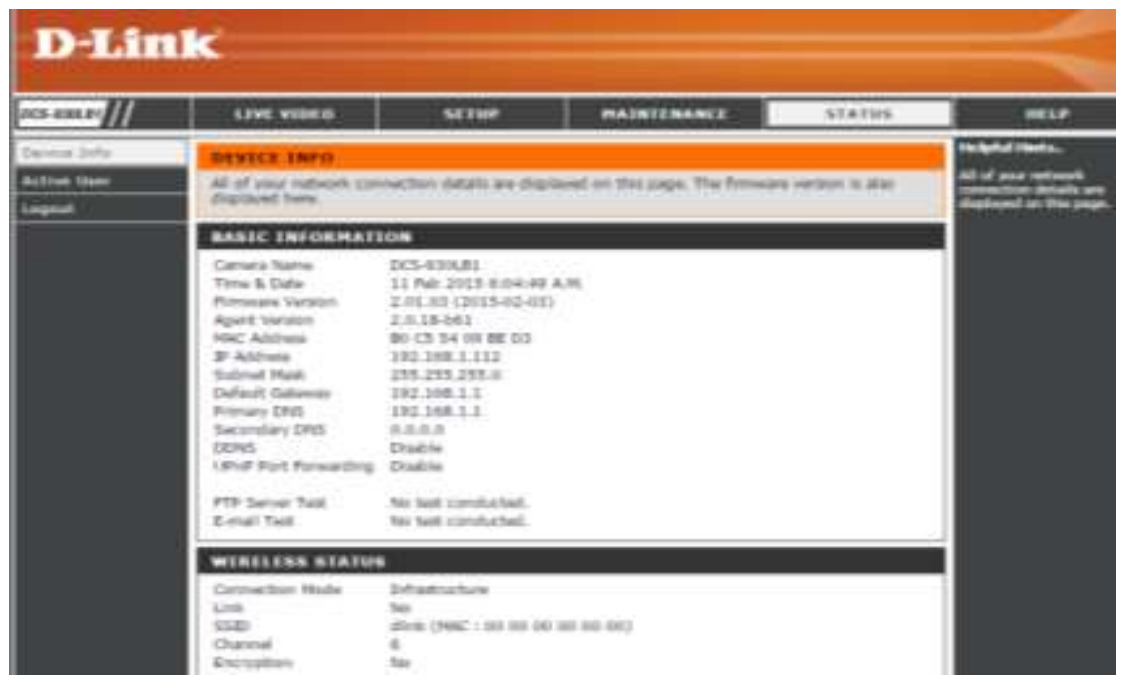

Gambar 10. Tampilan Status IP Camera pada Local Host

Gambar 10 memperlihatkan bahwa konfigurasi dan status IP Camera telah berhasil tehubung ke jaringan Internet. Langkah selanjutnya yaitu membuka tab baru di browser lalu mengetik default IP yang telah di konfigurasikan di dalam modem ADSL speedy yaitu “192.198.1.112". Setelah "Homepage" terbuka, IP Camera dapat dilihat aktivitasnya melalui Live Video dari Laptop. Untuk melihat aktivitas IP Camera dari Smartphone, terlebih dahulu download software "myD-Link lite" melalui PlayStore di Android dan AppStore. Hasilnya dapat dilihat pada Gambar 11.

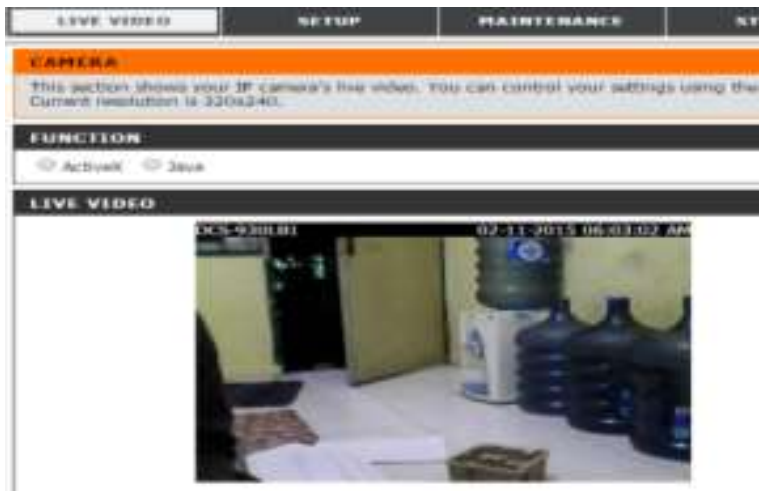

(a)

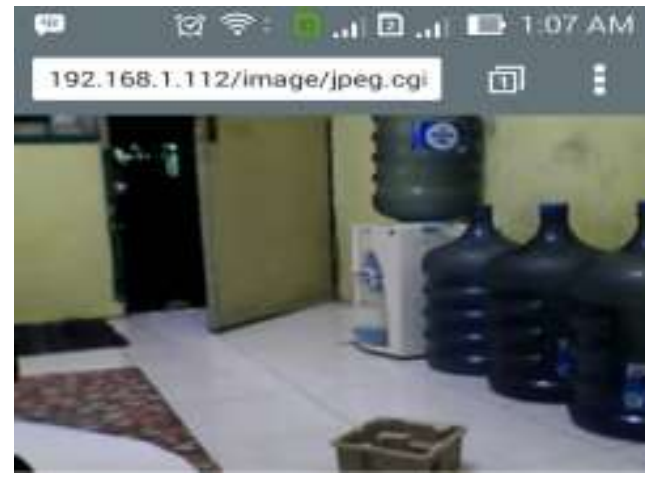

(b)

Gambar 11. (a) Live View Pada Laptop (b) Live View Pada Smartphone. 
Pemantuan video dapat menggunakan "ActiveX" pada OS Windows atau bisa mengunduh "Java" sebagai plug-in agar video dapat di putar. IP Camera juga dapat dilihat melalui software "D-ViewCam" yang bisa di install menggunakan CD driver IP camera D-Link.

Untuk mengetahui kehandalan sistem dilakukan pengukuran menggunakan wireshark, kemudian menghitung parameter QoS-nya. Gambar 12 merupakan capture dari pengukuran wireshark.

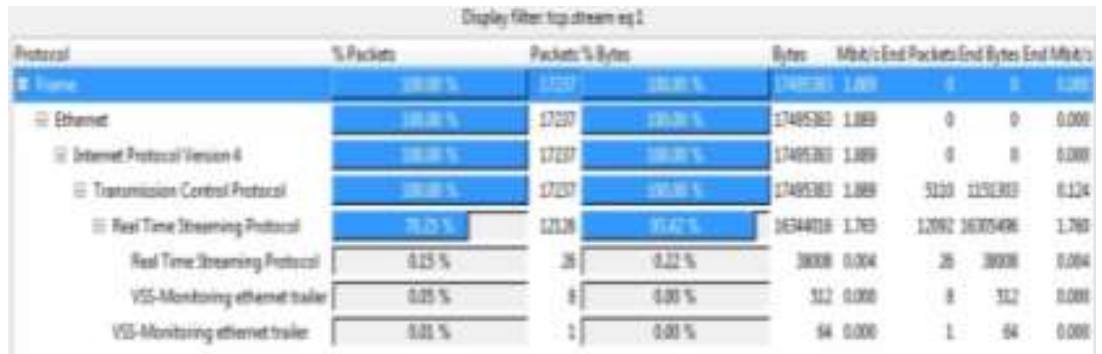

(a)

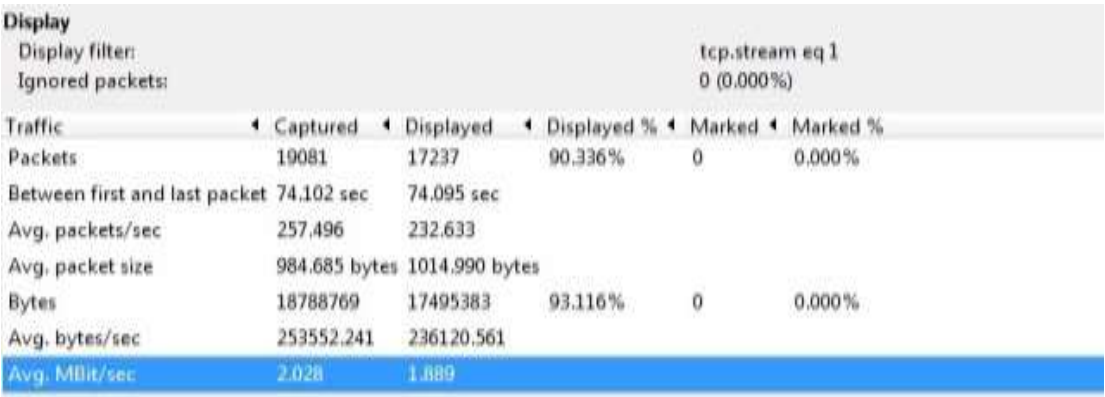

(b)

Gambar 12. (a) Tampilan statistik wireshark (b) Tampilan wireshark summary.

\subsection{Perhitungan Parameter QoS}

Dari Gambar 12(a),pada tampilan statistik wireshark diketahui nilai dari paket data yang dikirim dan diterima, sehingga packet loss dapat dihitung. Sedangkan dari Gambar 12(b) diperoleh nilai untuk perhitungan delay dan throughput. Adapun perhitungan dari packet loss, delay dan throughput adalah sebagai berikut:

* Packet loss $=\frac{\text { (packet data dikirim-packet data diterima) }}{\text { Paket data dikirim }} \times 100 \%$

* Packet loss $=\frac{(12126-12092)}{12126} \times 100 \%=0,2 \%$

* Delay $=\frac{(\text { between first and last packet })}{\text { packet }}=\frac{74,102}{19081}=0,0038 \mathrm{sec} /$ packet.

* Nilai throughput yang didapat yaitu 2,028 Mbit/sec.

\section{KESIMPULAN}

Dari hasil penelitian didapatkan bahwa CCTV mampu mendeteksi gerakan manusai dan merekam pada saat terjadi pergerakan berdasarkan perubahan suhu di ruangan. Dari hasil pengukuran yang dilakukan didapatkan bahwa Jarak maksimal PIR mendeteksi manusia adalah 4 meter. Setelah PIR berhasil mendeteksi manusia kemudian buzzer aktif, rata-rata lamanya buzzer menyala adalah 50.67 detik. Apabila buzzer aktif, maka sms akan terkirim secara otomatis pada smartphone, adapun delay rata-rata pengiriman notifikasi sms adalah 5.2 detik. Untuk mengukur kehandalan sistem dilakukan pengukuran parameter QoS menggunakan wireshark, adapun parameter yang diukur tersebut adalah packet loss sebesar 0,2\%, delay 0,0038 second/packet, dan throughput sebesar 2,028 Mbit/sec. 


\section{DAFTAR PUSTAKA}

[1] G. V Balakrishna and B. S. Kumar. SMART INTRUDER DETECTION USING VIDEO SURVEILLANCE. pp. 17-24.

[2] P. Chodon, D. M. Adhikari, R. Biswa, and S. Gyeltshen. 2013. Passive Infrared ( PIR ) Sensor Based Security System. Juni 2013. pp. 2-6.

[3] G. V. Kumar and G. V. R. Reddy. PIR \& WEBCAM BASED SECURITY ALERTNESS SYSTEM. pp. 208-215.

[4] S. Rackley. 2007. Wireless Networking Technology.

[5] G. Popovic, N. Arsic, B. Jaksic, B. Gara, and M. Petrovic. 2013.Overview, Characteristics and Advantages of IP Camera Video Surveillance Systems Compared to Systems with other Kinds of Camera. Int. J. Eng. Sci. Innov. Technol. vol. 2, no. 5. pp. 356-362.

[6] COMMSCOPE. 2007. Intelligent Building Infrastructure Solutions (IBIS). Juli 2007. pp. 1-2.

[7] R. a Y. Horak. 2007. Telecommunications and Data Communications.

[8] C. O. Ohaneme, J. Eke, A. C. O. Azubogu, E. N. Ifeagwu, and L. C. Ohaneme. 2012. Design and Implementation of an IP-Based Security Surveillance System. vol. 9, no. 5. pp. 391-400.

[9] L. Beddiaf. 2008. Vidéosurveillance. Principes et technologies.

[10] S. Li,. 2011.Network target: a starting point for traditional Chinese medicine network pharmacology. vol. 36, no. 15.

[11] M. Saleem and K. Doh. 2009. Generic Information System Using SMS Gateway. pp. 2-7

[12] M.- Volume and A. Agarwal. 2015. \& Management Technology Automatic Security with Laser Shooter by PIR Technology with LCD Pageant. vol. 2, no. 2. pp. 169-175. 